\title{
SISTEM INFORMASI PERSEDIAAN OBAT KLINIK TINE BERBASIS JAVA NETBEANS
}

\author{
Muhammad Fachri Muharam¹, Ahmad Suryadi², Ari Irawan³ \\ ${ }^{1,2,3}$ Universitas Indraprasta PGRI \\ Jl. Raya Tengah No. 80, Kel. Gedong, Kec. Pasar Rebo, Jakarta Timur 13760, Jakarta \\ $\underline{\text { 1imfachrii@gmail.com, }}{ }^{2}$ yadi281282@gmail.com, ${ }^{3}$ ari_irawan@unindra.ac.id
}

\begin{abstract}
ABSTRAK
Tujuan penelitian adalah membuat aplikasi siste informasi yang akan mempermudah pengguna dalam melakukan pendataan obat. Metode penelitian yang digunakan yaitu research and development yaitu melalukan sebuah penelitan dan mengembangkan sebuah produk yang sudah ada sebelumnya tahapan penelitian ini penulis melakukan wawancara dan observasi langsung ke tempat dan juga membaca penelitan terdahulu (studi literatur). Peneliianini dilaksanakan pada bulan Maret-Juli 2021.Lokasi yang menjadi tempat penelitian ini adalah Klinik Tine yang beralamat di Jl. Talas IV No.5, Pd. Cabe Ilir, Kec. Pamulang, Kota Tangerang Selatan, Banten 15418. Hasil penelitian diputuskan membuat sebuah sistem informasi persediaan obat berbasis java netbeans dan menggunakan MySQL untuk perancangan basis data, dengan menggunakan sistem informasi persediaan obat klinik tine dapat mempermudah pekerjaan admin dan apoteker. Kata Kunci: sistem informasi, persediaan obat, inventory klinik.
\end{abstract}

\begin{abstract}
The purpose of this research is to create an information system application that will make it easier for users to collect drug data. The research method used is research and development, namely conducting research and developing a product that already exists before this research stage the author conducts interviews and direct observations to the place and also reads previous research (literature studies). This research was carried out in March-July 2021. The location for this research is the Tine Clinic which is located at street Talas IV No.5, Pd. Chili Ilir, Kec. Pamulang, South Tangerang City, Banten 15418. The results of the study were decided to create a java netbeans-based drug inventory information system and use MySQL for database design, using the tine clinic drug inventory information system to simplify the work of admins and pharmacists.
\end{abstract}

Key Word: Information Systems, drugs inventory, clinic inventory

\section{PENDAHULUAN}

Saat ini Klinik Tine tersedia berbagai macam obat untuk beragam penyakit. Permasalahannya saat ini Klinik Tine masih menggunakan sistem manual. Dalam kasus ini masih melakukan pendataan obat dengan cara ditulis pada dengan microsoft word. Metode pendataan seperti ini menyebabkan banyak masalah salah satunya data obat menjadi tidak akurat dan dikhawatirkan terjadi kesalahan dalam pembuatan laporan. Menurut Hanik Mujiati (2013) diperlukan keakuratan data dan ketepatan waktu dalam melakukan aktifitas stok obat untuk menjaga kepuasan konsumen.

Karena dari itu penulis mencari penelitan sebelumnya dan menemukan sebelumnya Rohmayati dan Purnama (2017) pada Toko Obat Segar Waras Depok terjadi permasalahan khususnya dalam pengolahan data persediaan obat yang masih ditangani secara manual dimana setiap data harus diarsipkan menggunakan buku besar, mengakibatkan proses berjalan lebih lama dan kemungkinan banyaknya kesalahan yang terjadi, terutama dalam hal pencarian data stok obat. Maka Rohmayati dan Purnama memutuskan untuk membuat sebuah sistem informasi persediaan obat ini dirancang dengan menggunakan bahasa pemrograman Visual Basic 6.0 sebagai pengolahan data-data yang diperlukan, sedangkan databasenya menggunakan Microsoft Access 2007.

Penulis akan membuat sebuah sistem informasi persediaan obat untuk klinik tine. Sistem informasi ini dibuat khusus dan menyesuaikan kebutuhan pada klinik tersebut. Sistem informasi ini penulis buat dengan tujuan mempermudah pencatatan data obat dan kebutuhan lain yang berhubungan dengan data obat. Sehingga selain data obat akan ada juga data supplier, data pengguna, transaksi masuk, transaksi keluar, dan otomatis cetak laporan. 
Penulis menggunakan Netbeans 8.2 dan MySQL dalam proses pembuatan sistem informasi ini yang bisa dibilang lebih baru dari penelitian sebelumnya. Sehingga akan lebh mudah baik dalam proses pembuatan maupun penggunaan. Sistem informasi ini juga memiliki fitur membuat kategori obat dan terdapat nomor rak untuk peletakan obat dengan jenis tersebut, sehingga akan memudahkan pencarian obat baik secara langsung. Fitur lain yang diberikan adalah otomatis cetak laporan namun pengguna juga dapat melakukan filter tanggal atau mengatur rentang waktu data yang ingin dicetak.

\section{METODE PENELITIAN}

Penelitian dilakukan di Klinik Tine yang beralamat di Jl. Talas IV No.5, Pd. Cabe Ilir, Kec. Pamulang, Kota Tangerang Selatan, Banten 15418. Dalam kurun waktu 5 bulan penulis melakukan mengumpulkan data dengan metode kualitatif yang menurut gumilang (Galang Surya Gumilang, 2016) Penelitian kualitatif digunakan jika masalah belum jelas, untuk mengetahui makna yang tersembunyi, untuk memahami interaksi sosial, untuk mengembangkan teori, untuk memastikan kebenaran data, dan meneliti sejarah perkembangan. Maka dari itu penulis melakukan beberapa hal, seperti melakukan studi pustaka dengan membaca jurnal mengenai sistem informasi persediaan obat, melakukan wawancara secara langsung kepada pemilik klinik, dan observasi secara langsung untuk melihat kebutuhan sistem.

Pengembangan sistem menggunakan metode penelitian Research and development, yang menurut Wynarti (Wynarti, 2018) metode ini dapat menghasilkan suatu produk, dan menguji keefektifan produk tersebut. Pengembangan dilakukan mengembang sebuah perancangan sistem informasi pengolahan data obat klinik rafa berbasis java netbeans yang ditulis oleh Nasrudin, dkk (2014). Penelitian lain yang penulis jadikan referensi pengembangan adalah Analisis dan Perancangan Sistem Informasi Persediaan Obat pada Apotek Medical oleh ratnasari, dkk (Ratnasari, Dwi, Windi, 2016).

\section{HASIL DAN PEMBAHASAN}

\section{Proses bisnis}

Bidan jaga memberikan resep obat ke pasien lalu pasien akan memberikan resep obat ke apoteker setelah itu apoteker akan memberikan obat ke pasien sekaligus apoteker juga akan melakukan pengecekan jumlah obat. Jika jumlah obat sedikit maka apoteker akan memberitahu admin untuk melakukan pemesanan kepada supplier. Supplier menerima pesanan akan mengirimkan obat sesuai jumlah yang dipesan setelah barang sampai maka admin akan membuat laporan pemesanan dengan microsoft word untuk diberikan kepada pemilik klinik. Pemilik klinik menerima laporan persediaan data obat, transaksi keluar, transaksi masuk, data supplier, dan lain-lain pada akhir bulan.

\section{Rancangan sistem}

Penulis menggunakan diagram UML, yang menurut Rusdah (Rusdah, 2011) UML adalah bahasa yang dapat digunakan untuk menggambarkan, mendefinisikan, membangun dan membuat dokumen dari arsitektur menjadi perangkat lunak agar semua orang yang terlibat memahami arisitektur. UML dapat digunakan pada semua proses melalui metodologi pengembangan perangkat lunak dan melakukan implementasinya pada teknologi yang berbeda untuk menggambarkan sebuah sistem. Berbeda dengan Shouman Nugroho dan Dyan Retno Wardhani (Nugroho1 \& Wardhani, 2020) yang menggunakan DFD pada peneltian berjudul sistem pengolahan data barang berbasis java pada Rumah Sakit Olahraga Nasional, mengutip Prihandoyo (M Teguh Prihandoyo, 2018) yang mengatakan UML merupakan sebuah model perancangan sistem yang mempunyai kelebihan dapat memudahkan developer sistem dalam merancang sistem yang akan dibuat karena sifatnya yang berorientasikan pada objek. Berikut adalah diagram use case keseluruhan sistem informasi persediaan obat klinik tine. 


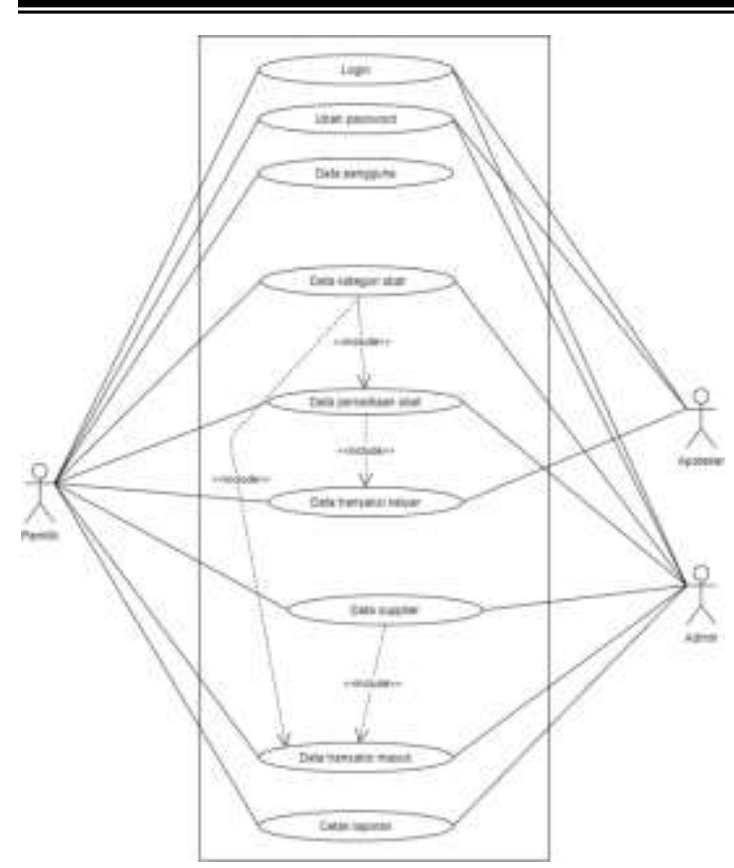

Gambar 1. Use case diagram aplikasi

Menurut Fauzan, dkk (Fauzan et al., 2021) use case diagram digunakan untuk menjelaskan persyaratan fungsi sebuah software. Use case dapat digunakan untuk menjelaskan bagaimana sistem itu bekerja. Digambarkan kalau pemilik dapat mengakses semua form. Sedangkan apoteker dan admin hanya beberapa form sesuai tugasnya masingmasing.

\section{Tampilan layar}

Berikut adalah hasil dari implementasi sistem persediaan obat pada Klinik Tine

\section{Tampilan login}

Ini adalah tampilan awal saat aplikasi dibuka, pada tampilan login pengguna harus memasukan username dan password yang sudah dimiliki/diberikan oleh pemilik klinik.

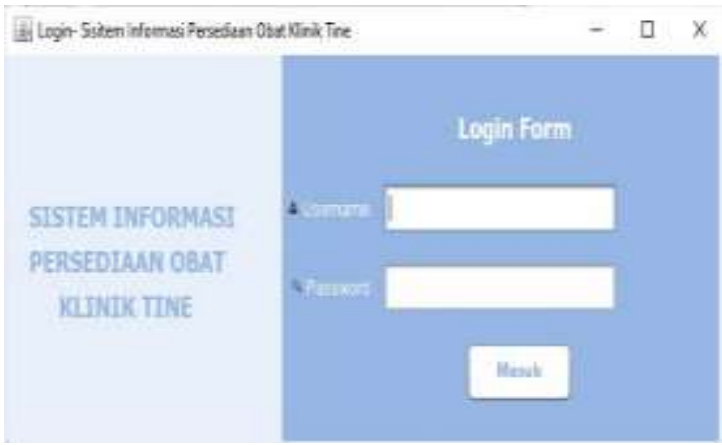

Gambar 2. Tampilan login

Pengguna diharuskan memasukan username dan password yang telah diberikan oleh pemilik, lalu klik tombol masuk untuk login.

\section{Tampilan menu utama}

Setelah login pengguna akan dialihkan ke menu utama yang digunakan untuk menampilkan semua form yang dapat digunakan oleh pengguna.

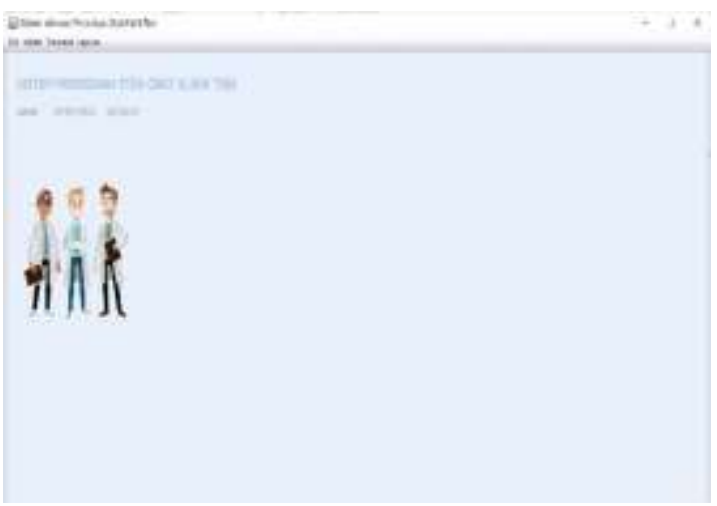

Gambar 3. Tampilan menu utama

Menu utam adalah form penghubung ke semua form, dibagian atas ada beberapa $s u b$ yang bisa diklik untuk mengarahkan ke form lain.

\section{Tampilan data persediaan obat}

Form ini digunakan oleh pemilik dan admin untuk sekedar melihat persediaan obat atau jika ingin menambahkan jenis obat baru.

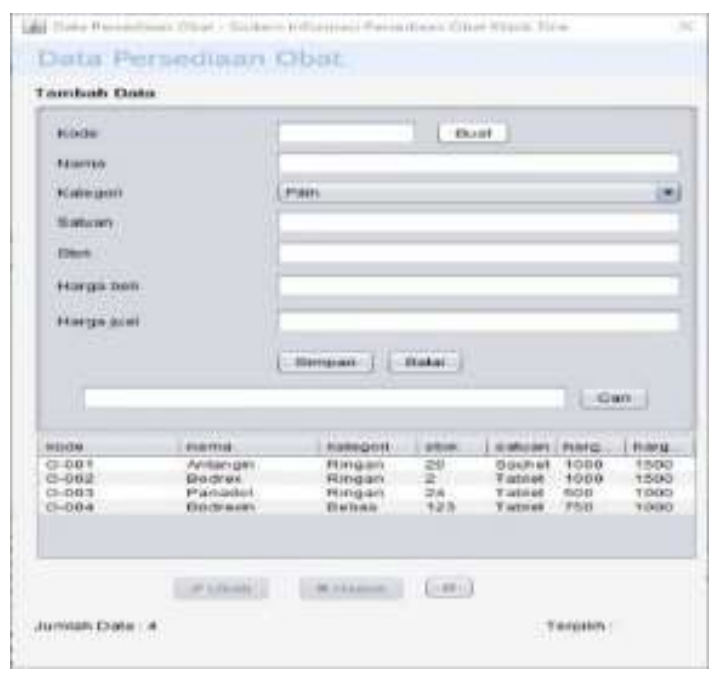

Gambar 4. Tampilan persediaan obat

Pengguna cukup klik tombol "buat" maka kode obat akan terbuat secara otomatis, lalu memasukan data obat, dan klik tombol simpan. Jika ingin mengubah data cukup klik data yang di tabel lalu klik tombol ubah, jika ingin menghapus yang cukup klik tombol hapus. 


\section{Tampilan transaksi masuk}

Form ini digunakan oleh admin jika ingin menambah stok obat yang masuk.

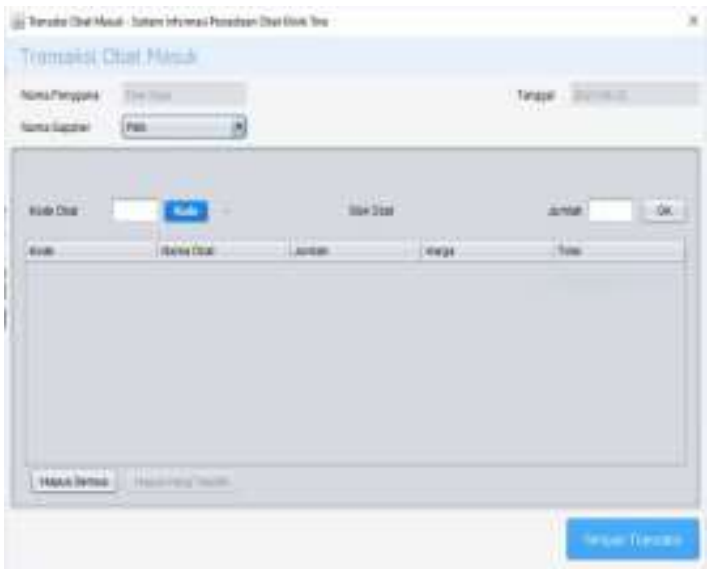

Gambar 5. Tampilan transaksi masuk

Pengguna pilih nama supplier obat, lalu masukan kode obat, jika lupa kode obat silahkan klik tombol "kode" yang akan memunculkan form data obat, lalu masukan jumlah obat, klik tombol "ok" ulangi proses diatas sampai selesai, jika sudah klik tombol "simpan transaksi"

\section{Tampilan transaksi keluar}

Form ini digunakan jika apoteker ingin melakukan transaksi keluar.

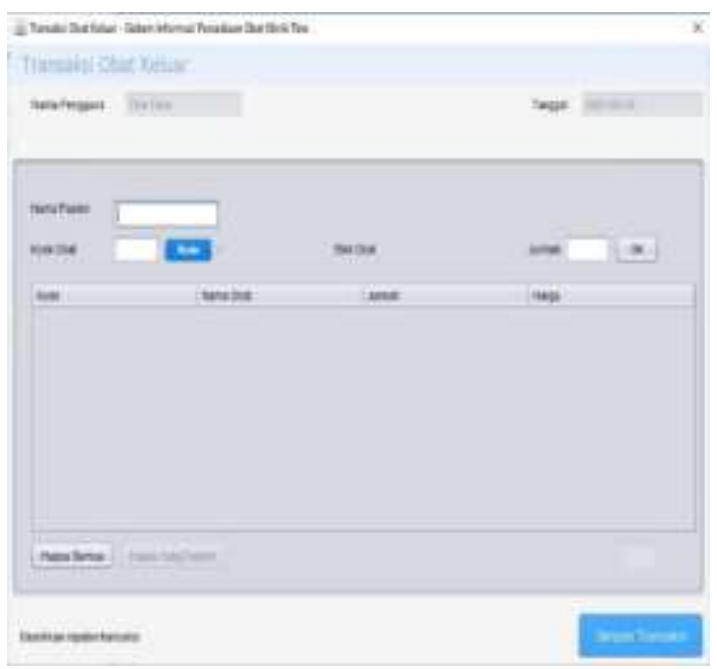

Gambar 6. Tampilan transaksi keluar

Masukan nama pasien, lalu masukan kode obat, jika lupa kode obat silahkan klik tombol "kode" yang akan memunculkan form data obat, lalu masukan jumlah obat, klik tombol "ok" ulangi proses diatas sampai selesai, jika sudah klik tombol "simpan transaksi"

\section{Tampilan data obat}

Form ini digunakan sebagai pengingat jika pengguna lupa kode obat.

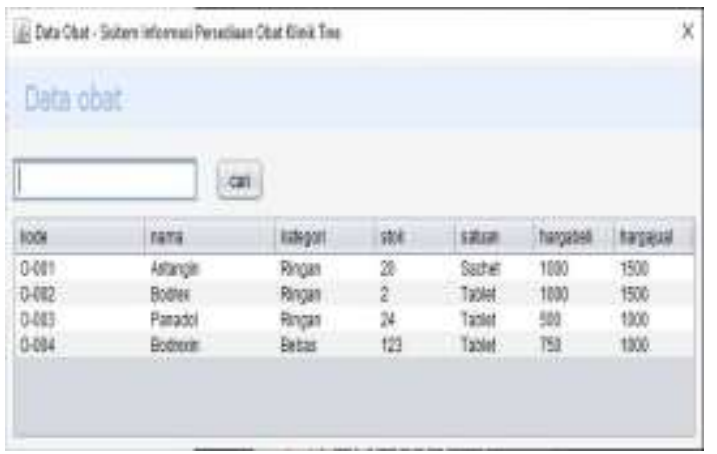

Gambar 7. Tampilan data obat

Masukan nama obat yang dicari, klik tombol "cari", maka data akan muncul di tabel, copy kode obat, keluarkan form data obat, dan paste kode obat di form transaksi.

\section{Tampilan cetak laporan/report}

Form ini digunakan jika admin ingin mencetak laporan yang akan diberikan ke pemilik.

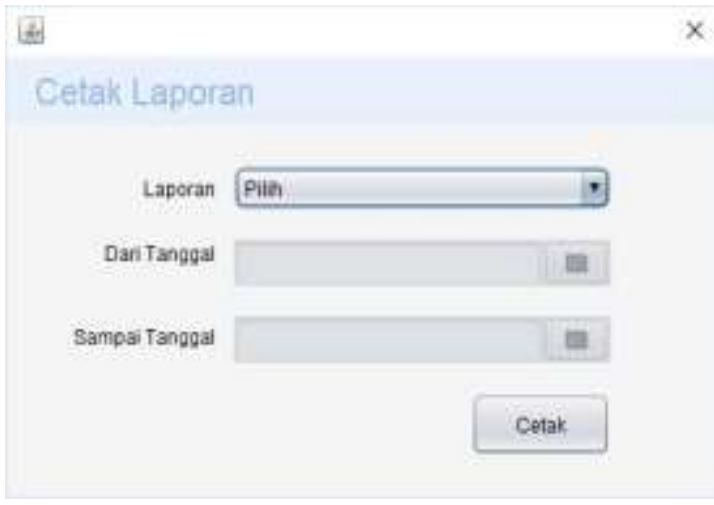

Gambar 8. Tampilan cetak laporan

\section{Tampilan keluaran}

Berikut adalah salah satu contoh hasil keluaran sistem informasi persediaan obat Klinik Tine berbentu laporan persediaan obat 


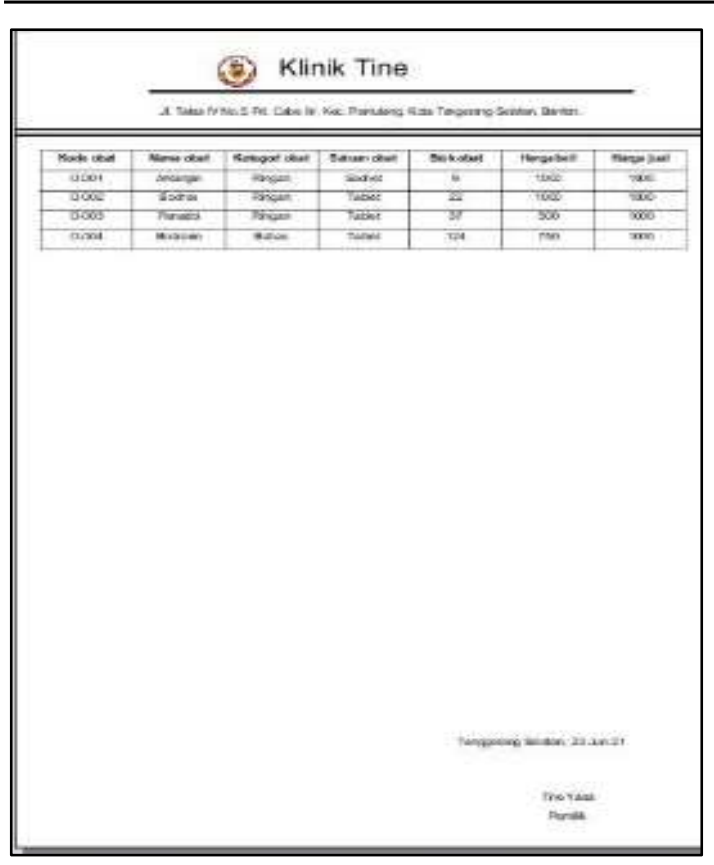

Gambar 9. Data persediaan obat

Pengguna bisa menekan icon "save" pada pojok kiri atas, lalu pilih format penyimpanan, maka laporan akan tersimpan dalam format tersebut.

\section{SIMPULAN DAN SARAN}

Berdasarkan hasil penelitian diatas, maka dapat disimpulkan kalau sistem informasi persediaan obat klinik tine membantu pendataan data obat dan membuat semuanya lebih efisien karena sudah terkomputerisasi. Berdasarkan hasil penelitian, saran yang dapat diberikan adalah sistem informasi persediaan obat klinik tine masih menggunakan jaringan lokal sehingga hanya bisa diakses dari klinik serta belum memiliki sitem auto backup data, mungkin kedepannya bisa dikembangkan lebih lanjut agar semakin efisien dalam penggunaannya.

\section{DAFTAR PUSTAKA}

Fauzan, R., Siahaan, D., Rochimah, S., \& Triandini, E. (2021). A Different Approach on Automated Use Case Diagram Semantic Assessment. International Journal of Intelligent Engineering and Systems, 14(1), 496505.
https://doi.org/10.22266/IJIES2021.022 8.46

Galang Surya Gumilang. (2016). Metode Penelitian Kualitatif dalam Bidang Bimbingan dan Konseling. Jurnal Fokus Konseling, 2(2).

Hanik Mujiati, S. (2013). Analisis Dan Perancangan Sistem Informasi Stok Obat Pada Apotek Arjowinangun. Indonesian Jurnal on Computer Science - Speed (IJCSS) FTI UNSA, 9330(2), 16.

M Teguh Prihandoyo. (2018). Unified Modeling Language (UML) Model Untuk Pengembangan Sistem Informasi Akademik Berbasis Web. Jurnal Informatika: Jurnal Pengembangan IT, 3(1), 126-129.

Nasrudin, N., Suryani, N., \& Buani, D. C. P. (2014). Perancangan Sistem Informasi Pengolahan Data. Jurnal Penelitian Teknik Informatika, 4, 35-45.

Nugroho1, S., \& Wardhani, D. R. (2020). Sistem Pengolahan Data Barang Berbasis Java Pada Rumah Sakit Olahraga Nasional. Semnas Ristek (Seminar ..., 22-28.

Ratnasari, Dwi, Windi, M. (2016). Analisis dan Perancangan Sistem Informasi Persediaan Obat pada Apotek Medical. 4(4), 423-433.

Rohmayati, A., \& Purnama, A. (2017). Sistem Informasi Persediaan Obat Pada Toko Obat Segar Waras Depok. Jurnal Bianglala Informatika Bianglala.Bsi.Ac.Id, 5(2), 70-76.

Rusdah. (2011). Analisa Dan Rancangan Sistem Informasi Persediaan Obat: Studi Kasus Puskesmas Kecamatan Kebon Jeruk. Jurnal TELEMATIKA MKOM, 3(2), 51-59.

Wynarti, I. A. (2018). Pengembangan Permainan Charades Sebagai Media Pembelajaran Materi Jenis-jenis Bisnis Ritel Kelas XI Pemasaran Di SMK Negeri 2 Buduran. Jurnal Pendidikan Tata Niaga (JPTN), 6(3), 63-70. 